\title{
Comparative evaluation of antioxidant drug influence on a radio therapy efficiency and oxidative status in mice
}

\author{
Alexander V. Siprov, I.M. Vashurkina, V.A. Masyagin
}

Medical Institute, Mordovia State University n.a. N.P. Ogaryov, Saransk, Russia

Accepted 23 May 2013

Original Text (C Siprov A.V., Vashurkina I.M., Masyagin V.A., 2012, published in Saratov Journal of Medical Scientific Research 2012; 8(4): 906-910.

\begin{abstract}
The aim of the study is a comparative analysis of the effect of melatonin (Melaxen) and 3-hydroxypyridine (Mexidol) on antitumor and antimetastatic influence of chemoradiotherapy and oxidative status at mice with Lewis lung carcinoma. Material Experiments have been organized on 95 mice of C57BI/6 line and of 20-22 g in weight. Cyclophosphan has been abdominally administered two times in a dosage of $60 \mathrm{mg} / \mathrm{kg}$ within the interval of 120 hours $-20-30 \mathrm{~min}$ before radiotherapy. It has been located on the area of initial tumor in a dosage of $2 \mathrm{~g}$ at the same time as cyclophosphan injection. Melaxen and Mexidol have been intramuscularly injecting in the dosage of 45 and $50 \mathrm{mg} / \mathrm{kg}$ for 14 days. Antitumor and antimetastatic effect of the applied therapy and changes in the oxidative status of the animals have been estimated. Results - Melaxen and Mexidol do not decrease antitumour and antimetastatic effects of radiotherapy and prevent the activation of free radical processes at animals with tumors. Mexidol was more effective than Melaxen in correction of superoxide dismutase activity in liver. The drugs under the study do not decrease radiotherapy-induced lipid peroxidation in the initial tumor. Conclusion - Melaxen and Mexidol do not decrease the radio therapy efficiency and oxidative status at mice with tumor (on the background of antitumor treatment).
\end{abstract}

Keywords: Melaxen, Mexidol, radiotherapy, oxidative status

Cite as Siprov AV, Vashurkina IM, Masyagin VA. Comparative evaluation of antioxidant drug influence on a radio therapy efficiency and oxidative status in mice. Russian Open Medical Journal 2013; 2: 0304.

Correspondence to Alexander V. Siprov. Address: room 79, 35, Kosareva str., Saransk, 430031, Russia. Phone: 88342351310. E-mail: alek-s13@mail.ru

\section{Introduction}

Chemo- and radiotherapy still keep being a major method in cancer treatment. However, evident toxic complications development limits maximum efficiency achievement. Extemporaneous gaps in treatment aggravate afterhistory of an anticancer therapy [1]. There different methods have been developed, which facilitate the realization of a maximum activity of the cytoreductive treatment usage in a clinic. The methods are organized in different directions including the reduction of the toxicity by antitoxic modifiers usage. A supportive care has firmly established itself in clinical oncology. It allows reducing the degree of severe complications, but not just prevent or reduce the drugand radiotherapy unwanted sequela caused by advanced oncological disease [2]. No less important is the fact that during the cancer progress there are changes of antioxidant status indices. This can influence tissues and organs. According to the medicine literature data peroxidation plays an important role in cancer emergence and progress [3-5]. Taking into account pathogenetic value of oxidative reactions in cancer process and antitumor treatment complications [6,7], there is a study of the antioxidant drugs efficiency. There were chosen the drugs with different mechanisms and influences on lipid peroxidation as antitoxic modifiers. At the same time the information about the influence of this medication on the specific potency of the chemoand radiotherapy is ambiguous and rare.

\section{Material and Methods}

Experiments are performed on 95 female-rats of the C57BI/6 line of 20-22 g in weight from the "Stolbovaya" [translit from Russian] nursery. The mice were contained in standard conditions of a State Mordovian vivarium under natural light regime, on a standard diet, having free access to food and water. All procedures with animals were organized according to European Convention for the protection of vertebrate animals used for experimental and other scientific purposes (Strasbourg, 1986). Lewis lung carcinoma (LLC) cell suspension ( 1 million cells in Hanks' solution) was intramuscularly passaged into the femoral area. The animals have been divided into 4 groups.

The study design is performed in Table 1 . The radiation of the animals had been organized with the help of the "Agat-R1" [translit from Russian] device. On the $22^{\text {nd }}$ day the mice have been withdrawn from the experiment under ether narcosis. Blood, different tissues and organs (liver, lungs, tumor node) of mice were used as a material. The efficiency of the treatment was estimated by the essential lesion volume and mass, antimetastatic effect was estimated by an average number of interfacial lung metastases for one animal and metastasis inhibition index (MII) [8]. To evaluate changes in lipid peroxidation (LPO) in blood serum there has been: a malondialdehyde (MDA) level determined, FeMDA (in reaction with thiobarbituric acid (TBA) using "Agat-Med» [translit from Russian] reagents kit for TBA-products test, including TBA-tasting probe incubation, the extraction of the butanol 
reaction products and spectrophotometric measurement of their content) and catalase potency [9], and in organs homogenates (liver, essential lesion) the MDA concentration, Fe-MDA, catalase potency and superoxide dismutase (SOD) [10]. During the statistical analysis of the research there had been the following indices determined: means (M), standard error of the mean $(m)$, metastasis inhibition index in percents. The normalcy of distribution was checked with the help of Kolmogorov-Smirnov's test. If the normalcy of distribution was proper the validity of the differences of the values was estimated using the Student's t-test. If there is non-normality the validity of the differences was estimated using the Mann-Whitney T-test. The differences were valid at $p<0.05$.

\section{Results}

The research of the antitumour effect after chemoradiotherapy and Melaxen in complex displayed that the reducing of the essential lesion did not differ from the same index in the group with chemoradiotherapy without Melaxen (excluding the $14^{\text {th }}$ day when the essential lesion growth was less; Figure). Comparator agent Mexidol also did not affect the reducing of the essential lesion. At the end of the experiment (on the $22^{\text {nd }}$ day) the essential lesion mass in a Cyclophosphan + radiotherapy $(\mathrm{CPH}+\mathrm{RT})$ group had reduced from $9.18 \pm 0.19 \mathrm{~g}$ to $6.97 \pm 0.18 \mathrm{~g}(\mathrm{p}<0.05)$. In the groups with complex of chemoradiotherapy, Melaxen and Mexidol the essential lesion mass did not differ from the same one in the $\mathrm{CPH}+\mathrm{RT}$, it was $7.24 \pm 0.3$ and $7.28 \pm 0.17 \mathrm{~g}$ respectively.

In the group of mice which had only CPH+RT the MII was $91.4 \%$, herewith the metastasing incidence had been slightly reduced comparing with untreated animals (Table 2). In mice which had a complex of chemoradiotherapy, Melaxen and Mexidol the MII and metastasing incidence did not differ from the same one in the $\mathrm{CPH}+\mathrm{RT}$ (Table 2).

Table 1. The study design

\begin{tabular}{ll}
\hline & \multicolumn{1}{c}{ Groups of animals }
\end{tabular}

Table 2. Antimetastatic efficiency indices of a complex chemoradiotherapy, Mexidol and Melaxen in mice with LLC (M $\pm m$ )

\begin{tabular}{lcc}
\multicolumn{1}{c}{ Group } & Animals with metastases, $\%$ & Average number of metastases \\
\hline LLC & 100 & $95.7 \pm 8.2$ \\
LLC+CPH+RT & 100 & - \\
LLC+CPH+RT+Melaxen & 83.3 & $8.2 \pm 2.2, \mathrm{p}_{1}<0.05$ \\
$\mathrm{LLC}+\mathrm{CPH}+\mathrm{RT}+$ Mexidol & 100 & $8.2 \pm 3.5, \mathrm{p}_{1}<0.05$ \\
\hline
\end{tabular}

$\mathrm{p}_{1}$ - the differences accuracy is calculated correspondingly to LLC group.

Table 3. Influence of the complex chemoradiotherapy and Melaxen treatment on lipid peroxidation process in mice with LLC (M $\pm m$ )

\begin{tabular}{|c|c|c|c|c|c|c|}
\hline \multirow[t]{2}{*}{ Parameters } & \multirow[t]{2}{*}{ Substratum } & \multirow[t]{2}{*}{ Intact animals } & \multicolumn{4}{|c|}{ Experimental Groups } \\
\hline & & & LLC (control) & $L L C+C P H+R T$ & $L L C+C P H+R T+$ Mexidol & $L L C+C P H+R T+$ Melaxen \\
\hline \multirow[t]{3}{*}{ MDA } & Serum & $3.52 \pm 0.38$ & $6.1 \pm 0.44, p_{1}<0.01$ & $4.2 \pm 0.74, p_{2}<0.05$ & $3.77 \pm 0.45, p_{2}<0.01$ & $2.85 \pm 0.55, \mathrm{p}_{2}<0.01$ \\
\hline & Liver & $8.7 \pm 0.96$ & $18.4 \pm 0.93, p_{1}<0.001$ & $10.7 \pm 1.17, \mathrm{p}_{2}<0.001$ & $6.88 \pm 1.07, \mathrm{p}_{2,3}<0.05$ & $5.18 \pm 0.76, p_{2,3}<0.01$ \\
\hline & Tumor node & - & $5.04 \pm 0.62$ & $10.99 \pm 2.21, p_{2}<0.01$ & $12.6 \pm 1.02, \mathrm{p}_{2}<0.001$ & $9.99 \pm 2.79, \mathrm{p}_{2}<0.05$ \\
\hline \multirow[t]{3}{*}{ Fe-MDA } & Serum & $4.69 \pm 0.48$ & $4.6 \pm 0.6$ & $3.68 \pm 0.67$ & $5.3 \pm 0.52$ & $4.2 \pm 0.66$ \\
\hline & Liver & $8.82 \pm 1.64$ & $23.9 \pm 2.28, p_{1}<0.001$ & $5.2 \pm 1.04, p_{2}<0.001$ & $5.89 \pm 0.88, \mathrm{p}_{2}<0.001$ & $5.99 \pm 0.87, p_{2}<0.001$ \\
\hline & Tumor node & - & $9.4 \pm 0.88$ & $4.84 \pm 0.77, p_{2}<0.01$ & $3.6 \pm 0.92, \mathrm{p}_{2}<0.01$ & $8.4 \pm 1.38, \mathrm{p}_{4}<0.05$ \\
\hline \multirow[t]{3}{*}{ Catalase } & Serum & $0.4 \pm 0.08$ & $0.17 \pm 0.01, p_{2}<0.05$ & $0.47 \pm 0.07, p_{2}<0.01$ & $0.56 \pm 0.08, p_{2}<0.001$ & $0.47 \pm 0.05, p_{2}<0.001$ \\
\hline & Liver & $0.19 \pm 0.02$ & $0.78 \pm 0.03, p_{1}<0.001$ & $0.16 \pm 0.03, p_{2}<0.001$ & $0.7 \pm 0.07, \mathrm{p}_{1,3}<0.001$ & $0.69 \pm 0.05, p_{1,3}<0.001$ \\
\hline & Tumor node & - & $0.89 \pm 0.02$ & $0.28 \pm 0.05, \mathrm{p}_{2}<0.001$ & $0.5 \pm 0.04, p_{2,3}<0.01$ & $0.35 \pm 0.05, \mathrm{p}_{2,4}<0.05$ \\
\hline \multirow[t]{2}{*}{ SOD } & Liver & $39.4 \pm 2.93$ & $35.87 \pm 0.48$ & $27.17 \pm 3.83, p_{1,2}<0.05$ & $28.54 \pm 4.67$ & $21.77 \pm 2.65, \mathrm{p}_{1,2}<0.01$ \\
\hline & Tumor node & - & $13.4 \pm 1.2$ & $46.3 \pm 6.67, p_{2}<0.01$ & $3.27 \pm 0.95, p_{2,3}<0.001$ & $3.49 \pm 0.63, p_{2,3}<0.001$ \\
\hline
\end{tabular}

$p_{1}$ - the differences accuracy is calculated correspondingly to intact animals; $p_{2}-$ to LLC group; $p_{3}-$ to LLC+CPh+RT; $p_{4}-$ to $L L C+C P h+R T+M e x i d o l$. 


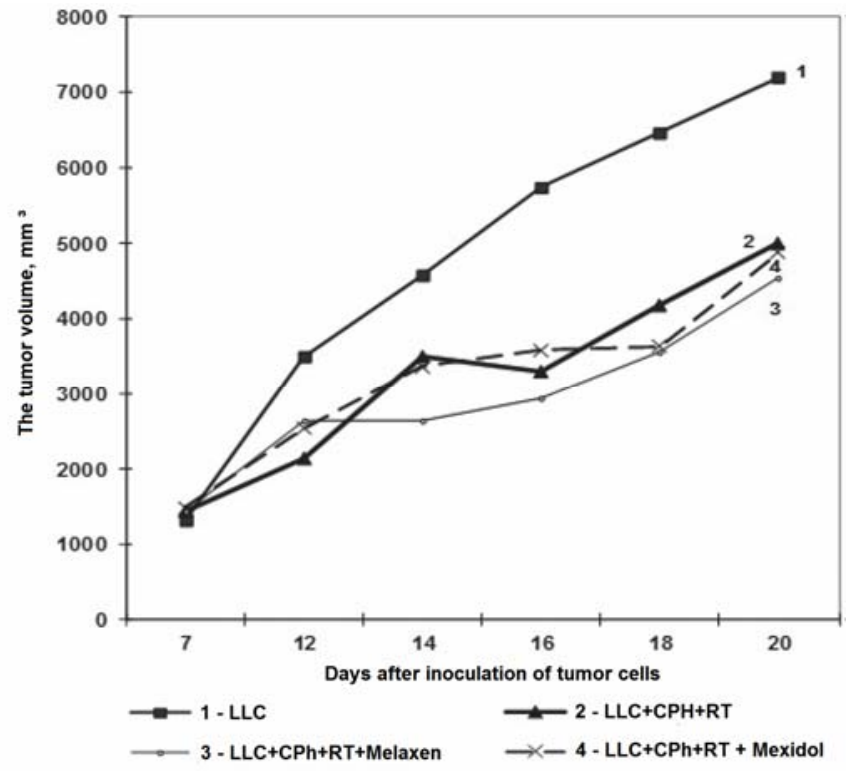

Figure. The LLC growth dynamics at mice during the complex Melaxen, Mexidol and chemoradiotherapy

With the estimation of the lipid peroxidation process status in animals it was denoted that in the group with chemoradiotherapy $(\mathrm{CPH}+\mathrm{RT})$ in the blood serum the MDA level was statistically valid reduced for $31 \%$, and catalase potency 2.8 times increased (for $276.5 \%)$ comparing with the control group. In animals with a complex of chemoradiotherapy and Melaxen the MDA level in a blood serum reduced for $53.3 \%(p<0.01)$ and catalase potency 2.8 times increased (for $276.5 \%)(p<0.001)$ comparing with the control group. In the group with Mexidol the MDA level reduced for $38.2 \%$, catalase potency 3.3 times increased (for 333.4\%) comparing with the control group (Table 3 ).

In the liver of the animals from the $\mathrm{CPH}+\mathrm{RT}$ group the had been fixed the reduction of the MDA and Fe-MDA level for $41.8 \%$ and $78.2 \%$ respectively $(p<0.001)$, catalase potency reduction for $79.5 \%$ (up to the intact animals index), and the SOD potency for $24.5 \%(p<0.05)$ comparing with the control group (Table 3).

Herewith the SOD potency was for $31 \%$ lower comparing with intact mice. In the $\mathrm{CPH}+\mathrm{RT}+$ Melaxen group the MDA decrease for $51.5 \%$ registered and catalase potency 3.3 times increased (for $331 \%$ ) comparing with the CPH+RT group, also the SOD potency decreased comparing with the control and intact animals for $39.5 \%$ and $44.7 \%$ respectively (Table 3 ).

During the complex of the chemoradiotherapy and Mexidol the MDA level had been reduced, and catalase potency had been increased for 35.7 and $337 \%$ (3.4 times) respectively comparing with the $\mathrm{CPH}+\mathrm{RT}$ group. But the SOD potency did not differ from the same at intact animals. In the lesion tissue at the animals from the $\mathrm{CPH}+\mathrm{RT}$ group there had been registered the MDA level 2.2 times increase (for 218\%), Fe-MDA level and catalase potency decrease for $48.5 \%$ and $68.5 \%$ respectively, the SOD potency 2.5 times increase (for $245.5 \%$ ) (Table 3). During the complex of the chemoradiotherapy and Melaxen treatment the MDA level had been increased for $98.2 \%$, and catalase potency decrease for $60.7 \%$, which did not differ from the corresponding indices in the $\mathrm{CPH}+\mathrm{RT}$ group. Herewith the Fe-MDA concentration did not differ from the same one in the control group, and the SOD potency had dropped greatly and it was for $74 \%$ lower than in the control group, and for $92.5 \%$ lower than in the $\mathrm{CPH}+\mathrm{RT}$ group (Table 3 ). During the complex of the chemoradiotherapy and Mexidol the MDA and Fe-MDA concentration did not differ from the same one in the $\mathrm{CPH}+\mathrm{RT}$ group, and catalase potency increased for $78.5 \%$ $(p<0.01)$, however, it had been stayed lower than in the control group for $43.8 \%(p<0.01)$. The SOD potency did not differ from the same one in the Melaxen group and it was lower for $75.6 \%$ comparing with the control group and for 93\% comparing with $\mathrm{CPH}+\mathrm{RT}$ group (Table 3).

\section{Discussion}

The results of the study displayed that Melaxen and Mexidol did not reduce the antitumour effect of the chemoradiotherapy. Antimetastatic effect of the complex of chemoradiotherapy, Melaxen and Mexidol did not reduce as well. During the estimation of the LPO processes there had been free radical processes with tumour registered. This is confirmed by the fact that there was the MDA level increase in liver and in blood serum, and in liver there had been registered catalase potency increase (which was of a compensatory origin). In a blood serum there had been catalase potency decrease because of the antioxidant system depression. The chemoradiotherapy had been limited the lesion progress and reduced the free radical intensity at animals, which was clear from the fact of the MDA level decrease in a blood serum and liver, and keeping catalase potency level at the level of intact animals indices. The SOD potency decrease was only in liver. However in the lesion there had been opposite changes registered: activation of the LPO process with MDA level increase and catalase potency decrease, the SOD potency increased as well. The complex Melaxen and chemoradiotherapy treatment, as well as with Mexidol, allowed to prevent more effectively the LPO processes at animals. This was confirmed by the MDA level decrease and catalase potency increase in liver (comparing with the chemoradiotherapy treatment only). But Mexidol prevented the SOD potency increase in liver more effective than Melaxen. In the lesion Melaxen and Mexidol did not defeat an intensified free radical activity, but reduced the SOD potency comparing as with the $\mathrm{CPH}+\mathrm{RT}$ group as with the control group (on the background of the MDA high level), which is coherent with the antioxidant selective effect on the normal tissues metabolism [11]. However Mexidol usage, in contrast with Melaxen, displayed catalase potency increase in a lesion. The data we have got are an experimental validation of the study of Melaxen and different antioxidant drugs usage as medications of an adjunct therapy in oncopathology, and enrich knowledge about Melaxen pharmacodynamics.

\section{Conclusion}

Thus, Melaxen and Mexidol equally do not reduce the chemoradiotherapy effectiveness. Melaxen and Mexidol in the whole prevent LPO process at animals with chemoradiotherapy, but in liver Mexidol resolves the SOD potency more effective than Malaxen. Both Melaxen and Mexidol do not reduce an intensified free radical progress in lesion.

\section{Conflict of interest}

All experiment and studies are organized on the authors' own behalf, without any sponsorship. There is no private and juridic persons' commercial interest in the result of the research. 


\section{Reference}

1. Chernichenko AV, Filimonov AV. Chemoradiation therapy of non-small cell lung cancer. Prakticheskaja onkologija 2008; 9(1): 16-20. [Article in Russian]

2. Konstantinova MM. New support means (antiemetics, bisphosphonates, colony stimulating factors). Prakticheskaja onkologija 2002; 3(4): 309-319. [Article in Russian]

3. Lebedeva VA, Pushkarev SV, Safronov ID, Trunov AN. Lipid peroxidation processes and antioxidant activity in advanced ovarian cancer patiens during polychemotherapy. Siberian Journal of Oncology 2007; (2): 42-45. [Article in Russian]

4. Men»wikova EB, Zenkov NK, Lankin VZ, et al. Okislitel»nyj stress: patologicheskie sostojanija i zabolevanija [Translit from Russian]. Novosibirsk, Russia, 2008. [Text in Russian]

5. Belonogov RN, Titova NM, Dychno YuA, Lapeshin PV, Kudryashova EV, Savchenko AA. Oxidative modification of plasma proteins and lipids of lung cancer patients. Siberian Journal of Oncology 2009; (4): 48-51. [Article in Russian]

6. Efremov AE, Ovsyanko EV, Tsyrendorzhiev DD, Michurina SV, Pakhomova YuV. Pro- and antioxidant activity of blood serum in rats with Walker-256 carcinosarcoma. Siberian Journal of Oncology 2009; (4): 58-60. [Article in Russian]

7. Svistunov AA, Chesnokova NP, Barsukov VYu, Selezneva TD, Zyablov EV. Activation of Lipoperoxidation Processes as a Typical Process of Cell Biomembrane Destabilization at Neoplasias of Different Localization. Saratov Journal of Medical Scientific Research 2010; 6(2): 267-270. [Article in Russian]

8. Guidelines for experimental (preclinical) studies of new pharmacological agents. R.U. Habrieva eds. Medicina Publ., Moscow, 2005. [Text in Russian]

9. Koroljuk MA, Ivanova Al, Majorova IG, et al. The method for determining the activity of catalase. Lab Delo 1988; (1): 16-18. [Article in Russian]

10. Chevari S, Chaba I, Sekej J. Role of SOD in oxidative processes cells and its method of determination in biological material. Lab Delo 1985; (11): 678-681. [Article in Russian]

11. Gorozhanskaja JeG, Patjutko Jul, Sagajdak IV. The role of alphatocopherol and retinol in the correction of lipid peroxidation of patients with malignant tumors of the liver. Problems in Oncology 1995; 41(1): 47-51. [Article in Russian]

\section{Authors:}

Alexander V. Siprov - MD, D.Sc., Assistant Professor, Pharmacology Department, Medical Institute, Mordovia State University n.a. N.P. Ogaryov, Saransk, Russia;

I.M. Vashurkina - MD, Post-graduate, Pharmacology Department, Medical Institute, Mordovia State University n.a. N. P. Ogaryov, Saransk, Russia;

V.A. Masyagin - Attending Physician, General Surgery Department, Medical Institute, Mordovia State University n.a. N. P. Ogaryov, Saransk, Russia. 